\title{
A gestão democrática no estado de Alagoas: do discurso oficial a um conflito de interesses
}

\section{Resumo}

Luciene Amaral da Silva ${ }^{I}$ Inalda Maria dos Santos ${ }^{I I}$

O artigo é parte da pesquisa de mestrado desenvolvida para o Programa de Pós-graduação em Educação da Universidade Federal de Alagoas, cujo objetivo foi investigar a presença de indicação de gestores dentro de um processo de gestão democrática em três escolas da rede estadual de ensino de Alagoas. A metodologia utilizada para a pesquisa qualitativa foi o estudo de caso, ancorada em entrevistas semi estruturadas para coleta de dados, com aprofundamento bibliográfico sobre o tema para a construção do referencial teórico. A pesquisa apontou que fatores como condições precárias de funcionamento das escolas públicas e uma legislação desatualizada são fatores que elevam o número de gestores indicados na rede.

Palavras - chave: Alagoas. Gestão Democrática. Legislação.

\section{Management in the democratic state Alagoas: the official discourse and a conflict of interest}

\begin{abstract}
The article is part of the research of master developed for the Graduate Program in Education of the Federal University of Alagoas, whose objective was to investigate the presence of indication of managers within a process of democratic management in three schools in the state education network of Alagoas. The methodology used for the qualitative research was the case study, anchored in semi-structured interviews for data collection, with deepening bibliographic review on the theme for the construction of the theoretical framework. The survey found that factors such as precarious conditions of operation of the public schools and an outdated legislation are factors that increase the number of managers indicated on the network.
\end{abstract}

Keywords: Alagoas. Democratic management. Legislation.

Artigo recebido em 12/03/2016 e aprovado em 02/04/2016. 


\section{O processo de implantação da gestão democrática na rede estadual de ensino de Alagoas}

Apesar do princípio da gestão democrática ser legitimado na Constituição Federal de 1988 mediante os movimentos sociais que lutavam desde a década de 1980 pela democratização do país, apenas em 1999, que tardiamente o estado de Alagoas implantou na rede estadual de educação, no governo de Ronaldo Lessa, a gestão democrática das escolas públicas com o instrumento de eleição direta para o provimento da função de gestor.

A partir de 1999, foi empreendida uma série de ações para a implantação da gestão democrática no estado, o Congresso Constituinte Escolar, que se tornou um espaço de discussão e avaliação de como a educação na rede estadual de ensino era tratada; em 2000, foi criada a Coordenadoria de Gestão Educacional, que implantou iniciativas na perspectiva de democratização da educação pública como a das eleições dos conselheiros escolares, a eleição direta para gestores, a descentralização dos recursos financeiros em 2003, culminando no Plano Estadual de Educação 2005-2015 ${ }^{\text {III }}$.

Segundo pesquisa de Araújo (2007), sobre a realidade da rede estadual de Alagoas na década de 1990, o caos alastrava-se por toda a rede educacional pelo fato das más condições de trabalho e de salários a que foram submetidos os professores, ocasionando sucessivas greves prolongadas que desencadearam abandono na matricula da rede estadual, demissão de mais de 15 mil professores, mostrando sinais de mudanças significativas somente a partir de 1998, a partir da aprovação do Fundo de Valorização do Magistério - FUNDEF, que levou estado e municípios ao incentivo para o aumento da matrícula dos alunos.

Ao pesquisar sobre o planejamento educacional em Alagoas no período de 1999 a $2004^{\mathrm{IV}}$, o autor aborda a questão da cultura da participação no processo de implantação da gestão democrática em Alagoas, em uma terra historicamente dominada pelo coronelismo ${ }^{\mathrm{V}} \mathrm{e}$ pela troca de favores que mantinha a dominação do poder oligárquico. Ele descreve em seu estudo todo o processo em detalhes da implantação da gestão democrática na rede estadual de ensino de Alagoas.

As ações que antecederam a implantação da gestão democrática como a criação das Unidades Executoras, em 1995, através do Decreto $\mathrm{n}^{\circ}$ 36.586, a criação dos Conselhos Escolares, em 1997, através da Lei Estadual no 5.945 sinalizavam pela inevitável implantação da gestão democrática no estado com base na participação da sociedade civil que se caracterizava mais pela fiscalização das ações do gestor do que participar da elaboração das políticas e ações da escola, bem como da construção do Projeto Político Pedagógico da escola.

Foi comentado que antes de 1999 havia ações por parte do estado que se pareciam com atitudes de democratização do sistema educacional, mas que não se efetivam pelo fato de que não possuíam uma visão ampliada do processo, tornando-se propostas fragmentadas. ${ }^{\mathrm{VI}}$

O I Congresso Constituinte Escolar ${ }^{\mathrm{VII}}$, ocorrido em 1999, significou a materialização e o ponto de partida das discussões sobre a escola que se tinha que não era nada atrativa naquele momento, e a escola que queria como proposta de participação da sociedade em definir o perfil da escola em que a sociedade alagoana almejava. 
Conhecendo a história de Alagoas, torna-se contraditório falar em uma cultura da participação em uma terra dominada pelo apadrinhamento em que a troca de favores políticos domina as relações de centralidade hierárquica no estado.

A forma de administração da educação em Alagoas esbarra sempre no fato de que "as ações idealizadas e formuladas enquanto políticas não passaram de adequação às exigências que se faziam em nível nacional para os sistemas educacionais, o que acabava por esbarrar na falta de vontade política de concretizá-la"VIII justificando porque a gestão democrática da educação não foi implantada desde 1988, como declarou a Constituição Federal.

No entanto, como a proposta da agenda de governo do então Ronaldo Lessa de envolver a sociedade no planejamento educacional do estado foi implantada na gestão democrática da educação via Secretaria de Estado da Educação - SEE/AL, pelas Coordenadorias Regionais de Educação - CREs e pelas escolas com o objetivo de tornar realidade a gestão democrática no estado.

Mais uma vez como aconteceu no país, em Alagoas, a gestão democrática da educação foi implantada partindo do governo central e não da sociedade civil, apenas alguns movimentos desencadeavam o desejo da democratização, mas a elaboração, construção e implementação ficaram a cargo do governo que a dirigiu de acordo com interesses políticos.

Mesmo com a participação proposta pelo governo como slogan de agenda governamental, é necessário distinguir que entre discutir e opinar e ter as decisões aceitas e colocadas no papel é outro caminho a percorrer.

A defesa de uma gestão democrática da educação que parte dos ideais de grupos organizados pela sociedade civil na busca pela democratização do país ainda depara-se com "uma participação decretada, instituída e regulamentada"IX

Segundo o mesmo autor, a implantação desse novo modelo de gestão em Alagoas deuse a partir da formação de um técnico de cada regional que atuava em doze cidades do estado na época e que fez a formação para seus técnicos sobre como a educação de Alagoas iria fazer para que a escola que existia fosse transformada na escola que a sociedade precisava.

Cada regional tratou de realizar o trabalho juntamente com as escolas, tendo sua culminância no I Congresso Constituinte Escolar que gerou a Carta de Princípios a ser implantados para que a gestão da educação acontecesse de forma democrática através da eleição de conselheiros escolares, como representação da comunidade, e a eleição para gestor, como forma de provimento da função.

$\mathrm{Na}$ Carta de Princípios da educação, foram sistematizados os anseios da sociedade civil quanto à implantação da gestão democrática na rede estadual de Alagoas. Dividida em três eixos, a Carta de Princípios trata da gestão, do pedagógico e do relacional como meios de garantia de uma escola de qualidade, segundo os princípios descritos abaixo selecionados pela relação que estabelecem com a implantação da gestão democrática.

\section{Quadro 1. Carta de Princípios da Educação: construindo a escola cidadã}




\begin{tabular}{|c|c|}
\hline EIXO & PRINCÍPIO \\
\hline EIXO DA GESTÃO & $\begin{array}{l}\text { 1.Que seja implantado o Conselho Escolar, com } \\
\text { representantes de todos os segmentos da } \\
\text { Comunidade Escolar (pais, alunos, professores, } \\
\text { corpo administrativo e apoio). } \\
\text { 3.Que haja eleição direta para gestores escolares. } \\
\text { 5. Que tenha direito ao voto todos os segmentos } \\
\text { da escola. }\end{array}$ \\
\hline EIXO PEDAGÓGICO & $\begin{array}{l}\text { 48. Que o PPP seja construído com toda a } \\
\text { comunidade escolar numa perspectiva de } \\
\text { transformação social. } \\
\text { 50. Que seja um suporte político-administrativo e } \\
\text { pedagógico da escola, definindo diretrizes e } \\
\text { orientações metodológicas numa concepção } \\
\text { democrática. }\end{array}$ \\
\hline EIXO RELACIONAL & $\begin{array}{l}\text { 66. Que sejam criados canais de participação dos } \\
\text { pais na escola, formando associações. } \\
\text { 67. Que a escola promova a participação no } \\
\text { gerenciamento dos recursos humanos, materiais e } \\
\text { financeiros, no processo de elaboração e } \\
\text { execução do plano de desenvolvimento da escola. }\end{array}$ \\
\hline
\end{tabular}

Fonte: Carta de Princípios da Educação. Maceió, 2000.

Com isso, percebe-se como o governo conduziu a implantação de uma forma democrática de gerir a educação e mesmo com tantas dificuldades, falhas e limites, foi implantada. Passados quatorze anos de sua implantação a respeito de como se encontra a gestão democrática no estado de Alagoas é o que será tratado no capítulo a seguir, que aborda a experiência realizada nas escolas da $6^{\text {a }}$ Coordenadoria Regional de Educação.

Muitas vezes, a legislação é construída com bases em interesses mais pessoais ou de um grupo pequeno, que a representação do desejo das maiorias. E as leis, em certos casos, deixam brechas para diversas interpretações. Lacunas, espaços de não comprometimento, são características também encontradas na legislação que trata da gestão democrática tanto em nível federal quando estadual o que será tratado com mais detalhe a seguir.

\section{O discurso oficial: do nacional ao local, um conflito de interesses}

As condições amplas que perpassaram a elaboração da Lei de Diretrizes e Bases da Educação Nacional - LDB de 1996 entregam o caráter intencional dos interesses de organismos internacionais na educação em todos os países. O modelo de educação que devia ser pregado estava em consonância com as diretrizes estabelecidas na Declaração de Jomtien em 1990.

A LDB “[...] se trata de um documento legal que está em sintonia com a orientação política dominante hoje em dia e que vem sendo adotada pelo governo atual em termos gerais e, especialmente, no campo educacional"X.

Uma lei cheia de conflitos e contradições que começou a ser discutida desde 1987 com o objetivo de discutir as diretrizes e bases da educação ${ }^{\mathrm{XI}}$. A luta pela democratização do país "norteou os eventos na área da educação, como a V Conferência Brasileira de Educação (CBE)"XII que trouxe o pensamento de uma escola efetivamente democrática. 
O artigo de Saviani que tratava do pensamento democrático da escola, escrito para a revista da ANDE (Associação Nacional de Educação) foi concluído em fevereiro de $1988^{\mathrm{XIII}}$. Com a aprovação da Constituição Federal, em 1988, que deixava a cargo de Lei complementar a elaboração das diretrizes e bases da educação nacional, que a proposta de formulação da nova LDB foi desenvolvida de forma a consolidar as bases de uma educação nacional e esse artigo de Saviani foi considerado como a origem da atual LDB.

Espero, enfim, que essas minhas reflexões sejam úteis no sentido de se encontrar os
caminhos para articular a escola elementar com o processo de democratização da
sociedade brasileira. [...]. A democratização da sociedade passa também pela
democratização da cultura. E não há democratização da cultura sem acesso aos
meios de expressão cultural e apropriação dos conteúdos básicos. E sem a mediação
da escola dificilmente se chega à apropriação das formas e conteúdos que
configuram o saber sistematizado $^{\text {XIV }}$.

No entanto, a nova versão da LDB só foi aprovada em 1996, depois de muitos acordos nesse jogo de interesses em defesa de uma escola pública para quem, interferindo em acertos como financiamento da educação através da responsabilidade do Estado, se a gestão da educação seria mais ou menos democrática, até que ponto a sociedade poderia decidir e como deixar as escolas sendo geridas pela sociedade sem interferir nos projetos de gestão do Estado?

Mesmo sendo aprovada com diversas lacunas e interrogações referente à gestão democrática da escola pública, a nova LDB deixou brechas para estados e municípios escolherem de que forma seria o provimento para a função de gestor escolar e as formas de participação da comunidade.

Art. $3^{\circ}$ - O ensino será ministrado com base nos seguintes princípios:

$[\ldots]$

VIII - gestão democrática do ensino público na forma desta Lei e da legislação dos sistemas de ensino ${ }^{\mathrm{XV}}$.

As sequências que foram recortadas da LDB apresentam pistas de interpretação que levam a perceber quais as intenções do jogo de interesse que se evidenciam em forma de texto presente nos artigos. A LDB precisar ter dispositivos mais claros sobre a gestão da educação a nível nacional, deixando essa tarefa para a Constituição Federal de 1988 que traz na matéria sobre educação a totalidade da organização e regulamentação legal ${ }^{\mathrm{XVI}}$.

$\mathrm{O}$ artigo $3^{\circ}$ aponta, de forma reduzida, para o fato de a gestão democrática ser exclusiva para as escolas públicas, excetuando as escolas privadas desse projeto, mais uma vez revelando a dualidade entre o público e o privado, apresentando o fato de que a legislação brasileira deve sempre reger as escolas públicas, como se as escolas privadas não fizessem parte do sistema, então torna-se uma falácia tratar em sistema no Brasil, pelo uso inadequado do termo sistema ${ }^{\mathrm{XVII}}$.

Na redação do artigo, o sentido aparece de forma clara em "e dos sistemas de ensino", deixar a cargo dos "sistemas" a regulação da gestão democrática é abrir espaço para a continuidade de uma gestão centralizada da educação nas mãos dos gestores políticos que perpetuam a forma de escolha do gestor da escola, com base na indicação condicionada aos interesses políticos de cada governo e de cada localidade, gerando uma diversidade de provimentos da função ${ }^{\text {XIII }}$. Sendo assim, o discurso oficial mascara a prerrogativa de 
manipulação de uma gestão para que ela seja apenas democrática no tocante a não prejudicar os "sistemas de ensino" e não a beneficiar a comunicar ou tornar, de fato, uma gestão da educação realmente democrática.

Aqui está presente não só o discurso dos órgãos responsáveis pela educação no Brasil voltada para uma sociedade justa e igualitária (ANFOPE, ANPAE, ANPED), como também está presente o discurso dos organismos econômicos que ditam as regras e regem a forma de organização dos países (UNESCO, Banco Mundial), distanciando do projeto oficial que foi também elaborado pela sociedade civil em diversos debates, sendo utilizada em contraposição ao que a sociedade almejava.

A forma de deixar a cargo dos sistemas incorpora-se a muitos discursos, tornando-se justificativa de municípios que ainda não implantaram a gestão democrática ou que implantaram a forma de representação dos segmentos através de um colegiado, mas que deixaram a escolha do gestor escolar ainda a cargo de interesses políticos, a referenciar a LDB como orientadora de tais práticas, como se verificou em alguns discursos dos entrevistados da pesquisa, que buscou analisar porque não houve eleição em algumas escolas da $6^{\mathbf{a}}$ coordenadoria de ensino em Alagoas, segundo os quais afirmaram que um dos motivos de haver indicação para o provimento da função de gestor escolar na rede estadual de Alagoas estava relacionado com a legislação estadual que não ampliava as oportunidades para outros membros da comunidade escolar.

Art. 14 - Os sistemas de ensino definirão as normas da gestão democrática do ensino público na educação básica, de acordo com suas peculiaridades e conforme os seguintes princípios:

I - participação dos profissionais da educação no projeto pedagógico da escola;

II - participação das comunidades escolar e local em conselhos escolares ou equivalentes ${ }^{\mathrm{XIX}}$;

$\mathrm{O}$ artigo 14 oferece elementos indefinidos ${ }^{\mathrm{XX}}$, evasivos e enfraquece a luta pela implantação da gestão democrática em todo o país. O referido artigo reforça, mais uma vez, que fica a cargo dos sistemas a implantação, bem como a forma de provimento da função de gestor, facilitando para os municípios a permanecerem com a indicação política como forma de atendimento às "peculiaridades" dos sistemas, segundo o mesmo artigo.

O que fica implícito no artigo é como se dará a materialização da participação da comunidade escolar e local na gestão, não estão definidos os caminhos que a comunidade poderia percorrer para também fazer parte da gestão, o que deixa subentendido é que a democracia, que estará presente na escola, será efetivada através da participação da comunidade na execução de tarefas ou no financiamento das ações da escola e não na elaboração, planejamento das ações, interferência nas decisões, fiscalização.

E quando o artigo apresenta que a participação da comunidade pode acontecer através de conselhos ou equivalentes, a legislação refere-se a equivalentes associações de pais e mestres, grêmio estudantil e outras formas de organização da comunidade que, em muitos casos, não contemplam toda a representatividade da comunidade escolar.

O que se deixa evidenciar na redação do documento é que se tornou um texto evasivo e que a forma de escrevê-lo evidencia o conflito de interesses entre o desejo da sociedade civil, em construir uma gestão da educação com bases democráticas, e a garantia das intervenções políticas na execução de tais determinações. O texto deixa implícito que se trata 
de uma democracia regulada, aquela que é dada à sociedade, mas sem perder todas as suas "rédeas" para garantia do controle e da soberania das classes.

Sendo assim, o que fica visível de análise e interpretação é que o discurso oficial tenta simular uma realidade que não existe em sua totalidade, ocultando uma proposta de democracia de fato e de direito que não é vivenciada dentro de uma sociedade de classes, mas que a torna legitima através dos documentos oficiais.

\section{A legislação estadual para gestão democrática: um entrave a novos rumos}

A gestão democrática em Alagoas, legalmente, teve início com a Lei Estadual no 5.945 de 25 de agosto de 1997 que dispõe, em seus artigos, sobre a criação dos Conselhos Escolares, visto que caberia a esse órgão colegiado a elaboração do processo de eleição direta dos gestores escolares.

A Carta de Princípios da Educação com o slogan construindo uma escola cidadã, em 14 de dezembro de 1999, trouxe, em forma de 68 princípios, as amarrações necessárias não só para a implantação da gestão democrática, mas como para o funcionamento da educação no estado. Em seguida, a Lei $n^{\circ}$ 6.152, de 11 de maio de 2000 instituiu as eleições diretas para diretores gerais e adjuntos nas escolas de educação básica da rede pública estadual. E, por fim, a Lei $\mathrm{n}^{\circ} 6.628$, de 21 de outubro de 2005, instituiu novas regras para a gestão na rede estadual de ensino a partir de 24 de outubro de 2005.

No entanto, a legislação mais recente que trata da orientação sobre a gestão democrática é de 2005, sem sofrer alterações nem atualização para reger os processos atuais de escolha de diretor, relegando a casos omissos, as situações que precisam de legislação própria para determinar.

A lei 6.628 , de 21 de outubro de 2005, instituiu as regras para a gestão democrática em Alagoas. O primeiro fato a observar é que as pesquisas utilizam o termo gestor escolar para designar a função do professor em cargo de chefia à frente de uma instituição escolar, enquanto a legislação estadual permanece com a nomenclatura Diretor e Diretor Adjunto configurando ainda termos outrora pertencentes a um conceito administrativo do papel do gestor. A defasagem da legislação é tão óbvia que ainda utiliza a nomenclatura $5^{\mathrm{a}}$ série no parágrafo $2^{\circ}$ no artigo $2^{\circ}$ para determinar que aluno que é impedido de votar:

$$
\begin{aligned}
& \text { Art. } 2^{\circ}[\ldots] \\
& \S 2^{\circ} \text { Para efeito desta Lei, a comunidade escolar é composta de todos os integrantes } \\
& \text { do magistério, funcionários administrativos, lotados e com exercício em uma das } \\
& \text { Unidades de Ensino, estudantes matriculados e com freqüência regular na Unidade } \\
& \text { de Ensino, maiores de } 14 \text { (quatorze) anos, cursando a partir da } \underline{5^{a} \text { série, e os pais de }} \\
& \text { alunos. }{ }^{\text {XI }} \text { (grifo nosso) }
\end{aligned}
$$

A lei traz os procedimentos sobre como deve ser feito o processo de escolha do diretor escolar. Da criação das comissões, passando por sua atribuição, até a nomeação feita pelo Secretário de Estado da Educação em documento oficial do estado.

O discurso oficial presente no texto da Lei 6.628/2005 segue a linha do discurso sobre democracia apresentado na LDB, só que de forma mais acentuada. Se a legislação considera o voto como a materialização da participação da comunidade escolar na construção de um 
processo democrático porque essa mesma legislação exclui uma faixa de alunos do processo de escolha do gestor escolar por considerá-los sem idade necessária para saber escolher.

$\mathrm{Na}$ eleição para conselheiro escolar, grande parte das escolas da rede estadual de ensino de Alagoas opta pela eleição direta e aberta, modalidade registrada em ata para que o procedimento seja menos dispendioso, já que as escolas não contam com recursos para financiamento de tais processos. Mesmo assim, a lei deixa claro que apenas os alunos que estiverem matriculados e frequentes a partir do $6^{\circ}$ ano do ensino fundamental podem votar independente da idade, mas os alunos menores de 14 anos e que estão matriculados nos anos inicias não têm direito ao voto, devem ser representados pelos pais.

\section{Art. $2^{\circ}[\ldots]$}

$\S 3^{\circ}$ Os estudantes maiores de 14 (quatorze) anos, cursando a primeira fase do Ensino Fundamental, serão representados por seus pais ou responsáveis. ${ }^{\text {XII }}$

O fato de excluir o aluno dos anos iniciais do processo aponta para uma questão contraditória ao que se vem defendendo ao longo da pesquisa: o incentivo à participação de todos os sujeitos que fazem parte da comunidade escolar, qual é jogo de interesse está nesse fato de excluir alunos do processo de votação do gestor escolar? E quais os argumentos para eximir tal aluno dos anos iniciais da votação? Qual o conceito de democracia em que a lei apóia-se para julgar inaptos os alunos matriculados nos anos iniciais? Por que um aluno de 13 (treze) anos matriculado no $4^{\circ}$ ano do ensino fundamental não pode votar e porque um aluno de 10 (dez) anos matriculado no $6^{\circ}$ ano pode votar em um professor para escolha do gestor escolar?

A redação do artigo $3^{\circ}$ da legislação estadual contribui para que o processo de da gestão democrática dê espaço, por sua vez, a indicação política como meio de provimento da função de gestor:

Art. $3^{\circ}$ Serão elegíveis para os cargos de Diretor Geral e Adjunto os integrantes do Magistério Público Estadual que tenham habilitação em nível superior com licenciatura plena e que estejam lotados e com efetivo exercício há mais de 1 (um) ano na Unidade Escolar. XXIII

A impossibilidade de efetivação desse artigo na rede pública de ensino de Alagoas tem sua base na escassez de professores do quadro efetivo do magistério, pelo fato de atualmente grande parte dos professores da rede aderir à aposentadoria ou por idade ou afastamento por doença, elevando a quantidade de professores contratados na rede pública que são impedidos pela legislação de candidatarem-se à referida função.

$\mathrm{Na} 6^{\mathrm{a}} \mathrm{CRE}$, nenhuma das 18 (dezoito) escolas da regional possui um quadro de professores efetivos completo, segundo dados da Unidade de Recursos Humanos da própria coordenadoria. Em todas as unidades de ensino, existem professores contratados com o objetivo de suprir a carência existente, mas que, mesmo assim, ainda não cobrem a carência total. Sabe-se que a modalidade de contratação desses professores faz parte de uma política de terceirização, de contenção de gastos, de redução de despesas, tornando precário o trabalho do professor e oferecendo uma educação de baixa qualidade, garantindo o controle dos conhecimentos divulgados pela escola com a proposta de domesticação dos sujeitos. 
A precarização da educação na rede estadual de Alagoas não se limita apenas à terceirização, mas a própria escassez de mão de obra, degradação dos prédios que abrigam as escolas e abandono em relação à segurança.

Duas escolas da regional apresentam um quadro defasado para seu funcionamento. Em uma existem apenas dois professores efetivos, uma está na função de gestora da escola e a outra esta na função de coordenadora pedagógica. Na segunda escola a situação ainda é mais grave: possui apenas uma professora do quadro efetivo que se encontra na função de gestora escolar. Como pela lei só pode ser eleita para dois mandatos então será mais uma escola a contabilizar os números de indicação na regional, caso nada seja modificado.

O fato da função de gestor escolar ser de exclusividade do professor do quadro do magistério público estadual dentro dessa realidade que é a grande falta de professores na rede, a legislação emperra a e não se visualiza a existência de outras possibilidades. Na escola, existem outros profissionais, que não estão na categoria de professor na rede estadual, mas exercem a função de professor em outra rede de ensino.

São professores habilitados para desempenhar a função de gestor escolar que atendem os requisitos de possuir licenciatura, ser lotado na escola há mais de um ano e ter experiência como professor em outra rede de ensino não é considerado, sendo preferível indicar politicamente outro professor que aproveitar esses profissionais.

Art. $3^{\circ}[\ldots]$

$\S 1^{\circ}$ Os candidatos deverão ter experiência mínima comprovada de 2 (dois) anos magistério, em qualquer órgão da educação federal, estadual, municipal ou particular. XXIV $^{\text {en }}$

Muito se tem questionado a SEE/AL para que esse também seja um caminho a ser utilizado como meio de garantia do direito de escolha da comunidade escolar, visto que professor é professor independente da rede de ensino, ele trará para qualquer escola sua experiência como professor, mesmo que desempenhando outra função na rede estadual.

Uma lei composta apenas de seis artigos, mas que termina sendo um empecilho ao processo de escolha dos gestores escolares diante da realidade das escolas da rede pública estadual de Alagoas. Diante de mais um processo de escolha de gestor escolar para o biênio 2015/2017, algumas escolas da 6 ${ }^{\text {a }}$ CRE, que estão mergulhadas num cenário de defasagem em seu quadro de professores efetivos, apontam para a indicação de mais professores.

Percebe-se até o momento que essa seção tratou do histórico da educação em Alagoas, como foi implantada e a presença do familismo, do favorecimento ${ }^{\mathrm{XV}}$ que perdura até os dias de hoje, bem como tratou da implantação da gestão democrática no estado de Alagoas como um projeto de governo e acabou firmando-se como política pública no estado.

\section{Considerações Finais}

A partir do conhecimento que fez trilhar o percurso reflexivo na trajetória dos conceitos, com base nas teorias e a partir do entendimento feito sobre a realidade investigada, vale-se de todo esse fio condutor para tecer algumas considerações que são relevantes neste artigo. 
Uma gestão democrática como afirmam Dourado, 1990; 1998; Gutierrez e Catani,1998; Paro, 2000; 2001; 2003; Silva Júnior, 2002; Bordignon e Gracindo, 2006; Lück, 2005; 2010, com base na participação, em que a comunidade representada no Conselho Escolar possa participar de forma consciente desde a elaboração do projeto da escola, passando pela execução, e finalizando com a avaliação de toda a sistemática de trabalho construído por todos e para todos, ainda é uma realidade distante de ser desenvolvida em grande parte das escolas da rede estadual de Alagoas.

As condições de trabalho ofertadas na rede estadual de Alagoas (escolas, na grande maioria, precisando de ampliação e reformas, quadro de professores e funcionários a cada ano continua mais escasso, ano letivo sendo concluído com falta de professores em algumas disciplinas) não motivam os professores a candidatarem-se à função de gestor escolar para gerir uma escola dentro de um cenário de falta de recursos para administrar.

Outro fato constatado na pesquisa foi referente à legislação do estado de Alagoas que trata da gestão democrática, está ultrapassada, desde 2005 que não sofre alterações, tornou-se um entrave aos avanços das normas que regem o processo de escolha para a função de gestor, por não buscar alternativas presentes na escola para resolver o problema da indicação.

A partir da análise das proposições que a legislação, tanto nacional quanto estadual, possibilitou observar que a legislação estadual de Alagoas não condiz com a realidade existente nas escolas alagoanas e que está se tornando um empecilho à abertura a novos rumos na gestão democrática da rede estadual.

Isto significa que, a legislação traz um caráter ideológico, dependendo do interesse do legislador sobre a pauta em questão, nesse caso específico a implantação da gestão democrática, e que as brechas ora encontradas nas análises de partes da legislação, demonstram claramente o jogo de interesses presente na execução das políticas educacionais. É para implantar a gestão democrática, mas não a democracia, uma contradição fruto do jogo de interesses que se entrelaça entre o dito, o escrito e o feito.

Assim, são necessários que sejam recolhidos elementos que dêem possibilidade ao aprofundamento da discussão com o intuito de contribuir não apenas com um projeto micro sobre a implantação legal da gestão democrática, mas que possa ser a vazão para o entendimento e posicionamento em nível macro dessa problemática que não deve ser apenas um fenômeno de Alagoas.

\section{Notas}

I. Mestre em Educação pela Universidade Federal de Alagoas ( UFAL). Pós-Graduada em Gestão de Recursos Humanos pela Fundação Getúlio Vargas - FVG (2004), em Educação e Desenvolvimento Agrário pela Universidade Estadual de Alagoas - UNEAL (2008) e em Tecnologia em Educação pela PUC-RIO (2010). Graduada em PEDAGOGIA pela Universidade Estadual de Alagoas - UNEAL (2003). O texto é parte da dissertação do Programa de Pós Graduação em Educação pela UFAL.

II. Possui graduação em Pedagogia (1997), Mestrado em Educação (2001) e Doutorado em Educação (2008), ambos realizados na Universidade Federal de Pernambuco. Atualmente é professora adjunta IV do Centro de Educação no curso de Pedagogia e no curso de Mestrado do Programa de Pós-Graduação em Educação da Universidade Federal de Alagoas. Atuou como Vice-Diretora da Associação Nacional de Política e Administração da Educação - ANPAE, seção Alagoas no período de 2013-2015 e participa na condição de líder e pesquisadora do Grupo de Pesquisa Gestão e Avaliação Educacional (GAE). Tem experiência na área de 


\section{A GESTÃO DEMOCRÁTICA NO ESTADO DE ALAGOAS: DO DISCURSO OFICIAL A UM CONFLITO DE INTERESSES \\ LUCIENE AMARAL DA SILVA E INALDA MARIA DOS SANTOS}

Educação, com ênfase em política educacional, financiamento da educação, planejamento e gestão escolar e educacional.

III. CRUZ NETO, Tiago Leandro da. Gestão Democrática da educação: uma discussão sobre planejamento educacional e participação coletiva em Alagoas (1999-2014). Maceió: EDUFAL, 2013.

IV. Ibid., 2013.

V. Movimento liderado por coronéis que tinha seu poder de mando acobertado pelo governador e que agia com desmandos impondo seu poder através da troca de favores.

VI. O Congresso resultou na construção da Carta de Princípios da Educação com o título "construindo uma escola cidadã”. A carta é composta por 68 princípios divididos em três eixos: gestão educacional, pedagógico, relacional.

VII. CRUZ NETO, Tiago Leandro da. Gestão Democrática da educação: uma discussão sobre planejamento educacional e participação coletiva em Alagoas (1999-2014). Maceió: EDUFAL, 2013. (p. 65-66).

VIII. Ibid., p. 47.

IX. Ibid., p. 55.

X. SAVIANI, Dermeval. A nova lei da educação: trajetória, limites e perspectivas. 11. ed. Campinas, SP: Autores Associados, 2008.( p.199)

XI. MELO, Kátia Maria Silva de. Discurso, Consenso e Conflito: a (re) significação da profissão docente no Brasil. Maceió, EDUFAL, 2011.

XII. CERVI, Gicele. Política de gestão escolar na sociedade de controle. Rio de Janeiro: Achiamé, 2013. (p. 107).

XIII. MELO, Kátia Maria Silva de. Discurso, Consenso e Conflito: a (re) significação da profissão docente no Brasil. Maceió, EDUFAL, 2011.

XIV. SAVIANI, Dermeval. O ensino básico e o processo de democratização da sociedade brasileira. Revista da ANDE, São Paulo, n. 7, 1984. (p. 13)

XV. BRASIL. Lei no 9.394, de 20 de dezembro de 1996. Estabelece as diretrizes e bases da educação nacional. Diário Oficial da União, Brasília, 23 de dezembro de 1996.

XVI. PARO, Vitor Henrique. Escritos sobre educação. São Paulo: Xamã, 2001.

XVII. SAVIANI, Dermeval. Educação Brasileira: estrutura e sistemas. 11. ed. Campinas, São Paulo: Autores Associados, 2012.

XVIII. DOURADO, Luiz Fernandes. (1990). Democratização da escola: eleições de diretores, um caminho?(1990), 176 f. Dissertação (Mestrado em Educação Escolar Brasileira) Universidade Federal de Goiás, Goiânia, 1990.

XIX. BRASIL. Lei no 9.394, de 20 de dezembro de 1996. Estabelece as diretrizes e bases da educação nacional. Diário Oficial da União, Brasília, 23 de dezembro de 1996.

XX. PARO, Vitor Henrique. Escritos sobre educação. São Paulo: Xamã, 2001.

XXI. ALAGOAS. Lei $\mathrm{n}^{\circ} 6.628$ de 21 de outubro de 2005. Institui novas regras para a gestão na rede estadual de ensino. Diário Oficial do Estado de Alagoas. Maceió, 24 de outubro de 2005.

XXII. Ibid., 2005.

XXIII. Ibid., 2005. 
XXIV. Ibid., 2005.

XXV. VERÇOSA, Elcio de Gusmão. Cultura e Educação nas Alagoas: história, histórias. 4 ed. Maceió: EDUFAL, 2006.

\section{Referências Bibliográficas}

ALAGOAS. Decreto no 36.586 de 06 de julho de 1995. Estabelece a criação das Unidades Executoras. Diário Oficial do Estado de Alagoas. Maceió, 1995.

Lei Estadual no 5.945 de 25 de agosto de 1997. Dispõe sobre a criação dos Conselhos Escolares. Diário Oficial do Estado de Alagoas. Maceió, 1997.

. Lei $\mathrm{n}^{\circ} 6.152$ de 11 de maio de 2000. Institui eleições diretas para diretores gerais e adjuntos nas escolas de educação básica da rede pública estadual. Diário Oficial do Estado de Alagoas. Maceió, 2000.

Carta de Princípios da Educação: construindo uma escola cidadã. Maceió, 2000.

Lei $\mathrm{n}^{\circ} 6.628$ de 21 de outubro de 2005 . Institui novas regras para a gestão na rede estadual de ensino. Diário Oficial do Estado de Alagoas. Maceió, 24 de outubro de 2005.

Portaria n. 839/2010. Institui a tipificação das escolas da rede pública estadual de Alagoas. Diário Oficial do Estado de Alagoas. Maceió, 2010.

BRASIL. Lei $\mathrm{n}^{\circ}$ 9.394, de 20 de dezembro de 1996. Estabelece as diretrizes e bases da educação nacional. Diário Oficial da União, Brasília, 23 de dezembro de 1996.

CERVI, Gicele. Política de gestão escolar na sociedade de controle. Rio de Janeiro: Achiamé, 2013.

CRUZ NETO, Tiago Leandro da. Gestão Democrática da educação: uma discussão sobre planejamento educacional e participação coletiva em Alagoas (1999-2014). Maceió: EDUFAL, 2013.

As representações sociais sobre a participação democrática de gestores de escolas públicas em Alagoas. Tese de doutorado. Recife, 2014.

DOURADO, Luiz Fernandes. (1990). Democratização da escola: eleições de diretores, um caminho?(1990), 176 f. Dissertação (Mestrado em Educação Escolar Brasileira) Universidade Federal de Goiás, Goiânia, 1990.

.A escolha de dirigentes escolares: políticas e gestão da educação no Brasil. In: FERREIRA, Naura Syria Carapeto (org.). Gestão democrática da Educação: atuais tendências, novos desafios. São Paulo: Cortez, 1998.

; COSTA, Messias. Escolha de dirigentes escolares no Brasil: relatório final de pesquisa. Brasília: ANPAE, 1998. 
MELO, Kátia Maria Silva de. Discurso, Consenso e Conflito: a (re) significação da profissão docente no Brasil. Maceió, EDUFAL, 2011.

PARO, Vitor Henrique. Por dentro da escola pública. 2 ed. São Paulo: Xamã, $1996 .$.

Administração escolar: introdução crítica. 9. ed. São Paulo: Cortez, 2000.

.Escritos sobre educação. São Paulo: Xamã, 2001.

SAVIANI, Dermeval. O ensino básico e o processo de democratização da sociedade brasileira. Revista da ANDE, São Paulo, n. 7, 1984.

A política educacional do Brasil. In: STHEFANOU, Maria e BASTOS, Maria Helena Câmara (orgs). Histórias e memórias da educação no Brasil. Petrópolis: Vozes, 2005.

A nova lei da educação: trajetória, limites e perspectivas. 11. ed. Campinas, SP: Autores Associados, 2008.

Educação Brasileira: estrutura e sistemas. 11. ed. Campinas, São Paulo: Autores Associados, 2012.

VERÇOSA, Elcio de Gusmão. Cultura e Educação nas Alagoas: história, histórias. 4 ed. Maceió: EDUFAL, 2006.

Intelectuais e processos formativos em Alagoas: (séculos XIX - XX). Maceió, EDUFAL, 2008. 